\title{
BMJ Open Effect of reimbursement restriction policy on the use of benzodiazepines in the Netherlands: an interrupted time series analysis
}

\author{
Lennart Jan Stoker, ${ }^{1,2}$ Eibert Roelof Heerdink, ${ }^{1,3}$ Richard Janssen, ${ }^{4,5}$ \\ Toine C G Egberts ${ }^{6}$
}

To cite: Stoker LJ, Heerdink ER, Janssen R, et al. Effect of reimbursement restriction policy on the use of benzodiazepines in the Netherlands: an interrupted time series analysis. BMJ Open 2019;9:e029148. doi:10.1136/ bmjopen-2019-029148

Received 21 January 2019 Revised 10 July 2019 Accepted 25 July 2019

\section{ABSTRACT}

Objectives Use of benzodiazepines has health risks. Reimbursement was restricted in the Netherlands from January 2009 onwards with the goal to reduce chronic use and healthcare expenditures. The aim of this study is to assess the initial and long-term effects of this policy on benzodiazepine use.

Design Interrupted time series analysis, segmented regression models, Kaplan-Meier survival analysis and Cox proportional hazards analysis.

Setting A 10\% random sample of benzodiazepine dispensings by outpatient pharmacies between January 2002 and August 2015 were obtained from the PHARM0 database. This database covered a catchment area representing about 3.6 million residents in 2015.

Participants 2500800 benzodiazepine prescriptions from 128603 patients were included.

Intervention Reimbursement restriction policy from January 2009 onwards.

Outcome measures Changes in: the volume of dispensed prescriptions and doses, the incidence, prevalence of incidental, regular and chronic use and discontinuation rates of benzodiazepines.

Results The volume of dispensed prescriptions and doses decreased by $12.5 \%$ (95\% Cl $9.0 \%$ to $15.9 \%$ ) and $15.1 \%$ $(95 \% \mathrm{Cl} 11.4 \%$ to $17.3 \%)$ respectively in January 2009 compared with December 2008. A clear initial effect on the overall incidence $(-14.7 \% ; 95 \% \mathrm{Cl}-19.8 \%$ to $9.6 \%)$ and the prevalence of incidental $(-17.8 \% ; 95 \% \mathrm{Cl}-23.9 \%$ to $11.7 \%)$, regular $(-20.0 \% ; 95 \% \mathrm{Cl}-26.1 \%$ to $13.9 \%)$ and chronic $(-16.0 \% ; 95 \% \mathrm{Cl}-23.1 \%$ to $8.9 \%)$ use was observed. A statistically significant reduction in the monthly trend per 1000 medication users was observed for the overall incidence $(-0.017 ; 95 \% \mathrm{Cl}-0.031$ to 0.003$)$ and the prevalence of incidental $(-3.624 ; 95 \% \mathrm{Cl}-4.996$ to 2.252$)$ but not for regular $(-0.304 ; 95 \% \mathrm{Cl}-1.204$ to $0.596)$ and chronic $(0.136 ; 95 \% \mathrm{Cl}-0.858$ to 1.130$)$ use. Patients who started treatment before policy had a slightly higher probability of discontinuation $(\mathrm{HR}=1.013 ; 95 \% \mathrm{Cl}$ 1.004 to 1.022$)$.

Conclusions The reimbursement policy had a significant initial effect on the volume, incidence and prevalence of benzodiazepine use. In addition, there is a statistically significant reduction in the monthly trend of overall incidence and of the prevalence of incidental use. No statistically significant reduction in the monthly trend
Strengths and limitations of this study

- The strengths of this study are the large sample size, long follow-up, large number of time intervals and presence of data of all outpatient prescriptions, including those initiated in secondary care. This makes it possible to focus on short-term and longterm effects.

- Another strength is use of an interrupted time series design to evaluate the effect of this policy change. This analysis is the golden standard for evaluation of the effects of policy change.

- This study has several limitations. First, it is difficult to attribute the observed changes in benzodiazepine use to a single intervention, the reimbursement restriction policy, because many confounding factors change in time. However, to our knowledge there were no other health system changes that could be a rival explanation for the observed changes.

- Second, due to PHARMO regulations, only a $10 \%$ random sample of PHARMO database was obtained and analysed. Nevertheless, the statistical significance of our analysis shows that the size of the data set is sufficient.

of chronic use, the main purpose of the reimbursement restriction, could be demonstrated.

\section{INTRODUCTION}

Benzodiazepines (BZD) are widely used in the treatment of panic disorders, anxiety, insomnia and epilepsy. In addition to beneficial therapeutic effects, chronic use of BZDs and BZD-related drugs can have health risks. It is associated with rebound insomnia, cognitive impairment and Alzheimer's disease, ${ }^{1}{ }^{2}$ increased injurious falls $^{3}$ and (hip) fractures, ${ }^{45}$ traffic accidents ${ }^{6}$ and increased (overdose) mortality. ${ }^{78}$ In patients with substance abuse disorders it is associated with dependence, and risk of misuse and abuse. ${ }^{9}$ International clinical guidelines therefore state that the pros and cons need 
to be carefully weighed when first prescribing a BZD to an individual patient and to restrict use to a short period. Despite increased awareness regarding risks associated with chronic use and recommendations to limit use in guidelines, these BZDs are among the most used medicines in developed countries. ${ }^{10}$ Based on data of all health insurers the prevalence of BZD use in the Netherlands was $10.75 \%$ in 2007; 1758665 users filled 11753939 prescriptions. ${ }^{11}$ Kurkoa et al estimated the prevalence of long-term use in the general population to be about $3 \%$, based on a systematic review of register-based studies on BZD use published in 1993-2014. ${ }^{12}$ The relative proportion of chronic use in adult BZD users ranges from $6 \%$ to $76 \% .{ }^{12}$ Chronic and excessive use became a public health issue and led to multiple campaigns to both reduce the prescription of these drugs and to stimulate discontinuation of chronic treatment. ${ }^{13}$

Worldwide different strategies have been used to reduce the use of BZDs. ${ }^{13-17}$ One of these strategies is to influence behaviour of patients, physicians and/or pharmacists by introduction of financial incentives, like pay for performance, copayments and restriction or termination of reimbursement. ${ }^{18}$ Since January 2009, BZDs are no longer reimbursed when used as anxiolytic, hypnotic or sedative in the Netherlands. The purpose of this policy change was to reduce chronic use and lower healthcare expenses. Coverage remained in case of epilepsy, palliative sedation and multiple psychiatric disorders, under the condition that the physician considered that no alternative treatment was suitable for the patient at hand. Before the introduction of this policy change, the Dutch Ministry of Healthcare calculated an annual net saving of $€ 70$ million for the years 2009-2013. ${ }^{19}$

Hoebert $e t$ al and Kollen et al studied the short-term effects of this reimbursement restriction in general practice. They showed that the policy change has led to a moderate decrease in BZD use in patients with newly diagnosed anxiety or sleeping disorder in general practice in $2009,{ }^{20}$ a decrease in the mean number of prescription days and a slight decrease in the number of long-term users in 2009 and 2010. ${ }^{21}$ However, the focus of their study was on newly diagnosed anxiety and sleeping disorders, general practice and the short-term effect of the policy change.

This study is an analysis of the reimbursement restriction in the Netherlands on the initial and long-term effects on the use of BZDs, in which the use is compared before and after the implementation of reimbursement restriction in January 2009.

\section{METHODS}

\section{Setting}

Data for this study were obtained from the PHARMO Outpatient Pharmacy Database (www.pharmo.nl). This database comprises general practitioner (GP) and specialist-prescribed medication dispensed by the outpatient pharmacy. The dispensing records include information on type of product, date, strength, dosage regimen, quantity, route of administration and prescriber specialty. Records are coded according to the WHO Anatomical Therapeutic Chemical (ATC) Classification System. Outpatient pharmacy data cover a catchment area representing about 3.6 million residents in 2015; almost a quarter of the Dutch population. Patient information includes gender, year of birth and socioeconomic status. Each patient is identified with an anonymous unique patient identification code that enables the observation of patient drug use in time.

In the Netherlands the coverage of pharmaceutical care is regulated by the Health Insurance Act. ${ }^{22}$ The Ministry of Health, Welfare and Sport and the Healthcare Institute of the Netherlands decide which drugs fall under the mandatory health insurance package. Registered medicines have to be assessed before they can be included in the Medicines Reimbursement System (GVS). Medicines listed in the GVS are fully or partially reimbursed by health insurers. Once a year the Ministry of Health, Welfare and Sport evaluates and actualises the list in order to keep healthcare affordable.

This research was done without patient involvement. Patients were not invited to comment on the study design and were not consulted to develop patient-relevant outcomes or interpret the results. Patients were not invited to contribute to the writing or editing of this document for readability or accuracy.

\section{Study population}

All medication records of a random $10 \%$ selection of all patients included in PHARMO who received at least one prescription for an oral BZD in the time period between January 2002 and August 2015 were collected and included. Due to the exceeding of the maximum allowed quantity of records by PHARMO a $10 \%$ sample was made available for this study. In the Netherlands, the following oral BZDs were available and dispensed during the study period: anxiolytics (N05BA: diazepam, chlordiazepoxide, oxazepam, clorazepate, lorazepam, bromazepam, clobazam, alprazolam), hypnotics and sedatives (N05CD: flurazepam, nitrazepam, flunitrazepam, lormetazepam, temazepam, midazolam and N05CF: zopiclone, zolpidem) and antiepileptics (N03AE01: clonazepam).

\section{Outcome measures}

To estimate the effect of the policy change on the use of BZDs on population and patient level, the following four outcome measures were defined: dispensing volume, incidence, intensity and discontinuation of BZD use.

Volume of dispensed BZDs: dispensed prescriptions and dispensed defined daily doses

First, to estimate the effect of the policy change on the total volume of BZD use, two outcome measures were chosen: the total number of dispensed prescriptions and the total amount of dispensed defined daily doses (DDD). The DDD is the assumed average maintenance dose per 
day for a drug used for its main indication in adults defined by the WHO. The purpose of the ATC/DDD system is to serve as a tool for drug utilisation monitoring and research in order to improve quality of drug use.

The total number of dispensed prescriptions and the total amount of dispensed DDDs per month were calculated. To correct for changes in the size of the dynamic population over time, $10 \%$ of the total number of medication users present in de PHARMO-database was calculated per month. This figure is then used as denominator to calculate the monthly dispensing rate and $D D D$ rate per 1000 medication users.

[number of dispensed presciptions

in $10 \%$ sample]

$$
\text { dispensing rate }=\frac{\text { per month }}{10 \% *[\text { number of medication users present }} * 1.000
$$

in PHARMO database]

per month

[sum of dispensed DDD

in $10 \%$ sample]

per month

DDD rate $=\frac{\text { per month }}{10 \% *[\text { number of medication users present }} * 1.000$

in PHARMO database]

per month

\section{Incidence of BZD use}

Second, the incidence of BZD use was assessed. Incidence of use was defined as the absence of BZD use within 3 months before a prescription was dispensed. The total number of medication users present per month in de PHARMO-database was used to calculate the incidence. The incidence therefore reflects the frequency of starting a BZD per month.

Intensity of prevalent BZD use: incidental, regular and chronic use Third, the intensity of BZD use was assessed among prevalent users. Prevalent use was defined as the presence of at least one dispensed prescription in a calendar year. For each prevalent BZP user, the BZD use was classified as 'incidental', 'regular' and 'chronic' based on the number of days of use within 365 days after the first dispensed prescription in a calendar year; that is, $1-30$ days, 31-180 days and more than 180 days. The intensity of each prescription was calculated using the dispensed quantity and the dose regimen. In case of missing data, the duration of prescriptions was set on 30 days, which is the maximum dispensed quantity for BZDs in the Netherlands.

\section{Discontinuation of BZD}

Fourth, the treatment discontinuation of all prevalent BZD users was assessed. Discontinuation was defined as the absence of a BZD prescription within 91 days after the theoretical end date of the last BZD prescription. KaplanMeier survival curves were constructed to visualise the
Table 1 Possible effects of policy change in general

\begin{tabular}{|c|c|c|}
\hline Effect type & Level effect & Delta slope (trend) \\
\hline $\begin{array}{l}\text { Initial and long-term } \\
\text { effects }\end{array}$ & Decrease & Negative \\
\hline Initial effect only & Decrease & No change \\
\hline $\begin{array}{l}\text { Initial effect and long- } \\
\text { term opposite effects }\end{array}$ & Decrease & Positive \\
\hline Long-term effect only & No change & Negative \\
\hline No effect & No change & No change \\
\hline
\end{tabular}

difference in time to discontinuation between patients starting BZD use in the years 2004-2008 (before policy change) and 2009-2013 (after policy change).

\section{Data analysis}

The primary statistical model for the effect of the policy change on the dispensing rate, DDD rate, incidence and prevalence of BZD use was segmented regression, which is commonly used for estimating the effects of interventions in interrupted time series (ITS) studies. ${ }^{23-25}$ The Cochrane Collaboration Guideline on ITS was used, applying a segmented regression model. ${ }^{26}$ Because the announcement of the policy change in September 2008 could have influenced the number of filled prescriptions due to anticipation, the data of the last 3 months before, and the first month after the intervention were excluded from the models. For methodological reasons, it is not possible to calculate the prevalence of initial, regular and chronic use for the years 2014 and 2015. A least squares regression line of predicted values is fitted in each segment, with the assumption of a linear trend over time. The goodness of fit of the models is provided with the $\mathrm{R}^{2}$ value.

In an ITS model, policy effects can be measured as a change in the slopes before and after policy, indicating the monthly trends, and the change in level after the implementation of the policy. Based on this analysis, table 1 gives a summary of possible effects from statistical analysis.

Cox proportional hazards analysis was applied to estimate the strength of the association between the 5-year period before and after policy and the risk of discontinuation, and was expressed as an HR with 95\% CIs. Observations were censored at the 3 months before and at the 1 month after the policy change. Age, sex and socioeconomic status were considered potential confounders. Confounders resulting in a change of more than $10 \%$ in the risk estimate were included in the final model.

A sensitivity analysis was conducted to assess the influence of our definition of BZD discontinuation by expanding the 91-day period to 182 and 365 days and by defining incident as not having dispensed a BZD in the 182 and 365 days before.

SAS Enterprise Guide V.7.1 (SAS Institute) and FoxPro V.6.0 (Microsoft, Redmond, Washington) were used for 
data extraction and analysis. Statistical analyses were performed in SPSS V.24 (SPSS).

\section{RESULTS}

\section{Sample characteristics}

A total of 2500800 filled prescriptions for oral BZD for 128603 unique patients were identified and included. Absolute sample characteristics per year are shown in table 2. Due to the dynamic character of the size of this database throughout the years the absolute number of patients and prescriptions fluctuates. The number of female BZD users is about twice as large as the number of male users. This ratio does not change substantially over time. The proportional use between the different age groups slowly shifts over time to an increase in the percentage of users over 65 years.

\section{Effect analysis}

The effect of the policy on the volume; dispensing rate and on the dispensed DDD rate

Figure 1A shows the dispensing rate trend for BZDs, with a distinction between raw and estimated trends and upper and lower confidence limits $\left(\mathrm{R}^{2}=0.75\right)$. At the beginning of the study the estimated dispensing rate was 114.4 (95\% CI 102.9 to 125.8$)$ per 1000 medication users per month. The estimated dispensing rate decreased by $12.5 \%(95 \%$ CI $9.0 \%$ to $15.9 \%$ ) from 107.2 to 93.8 in January 2009 just after the reimbursement restriction, which shows that the level of the filled prescription rate changed significantly. In contrast, prepolicy trend $(-0.085, \mathrm{p}=0.002)$ was not significantly different from the postpolicy trend $(-0.063, \mathrm{p}=0.029)$; the monthly trend change after policy was 0.022 (95\% CI -0.056 to 0.100$)$ per 1000 medication users. Therefore, a long-term effect was lacking, so the policy had only an initial effect on the dispensing rate.

Figure $1 \mathrm{~B}$ presents the monthly $D D D$ rate, with a distinction between raw and estimated trends and upper and lower confidence limits $\left(\mathrm{R}^{2}=0.92\right)$. At the beginning of the study the estimated DDD rate was 2274 (95\% CI 2072 to 2476) per month per 1000 medication users. The $D D D$ rate decreased significantly by $15.1 \%$ (95\% CI $11.4 \%$ to $17.3 \%$ ) from 1811 to 1538 in January 2009, just after the reimbursement restriction. The prepolicy trend $(-5.85$, $\mathrm{p}<0.001)$ was significantly different from the postpolicy trend $(-2.82, \mathrm{p}<0.001)$; the monthly trend change after policy was 3.033 (95\% CI 1.592 to 4.474 ) per 1000 medication users. Therefore, the policy had, according to our definition, an initial effect and a long-term opposite effect on the $D D D$ rate.

\section{The effect of the policy on incidence of BZD use}

Figure 2A shows the monthly incidence of BZD use, with a distinction between raw and estimated trends and upper and lower confidence limits $\left(\mathrm{R}^{2}=0.77\right)$. At the beginning of the study the estimated incidence in April 2002 was 12.9 (95\% CI 11.1 to 14.7 ) patients per month per 1000 medication users. The estimated incidence decreased significantly by $14.7 \%$ (95\% CI $9.6 \%$ to $19.8 \%$ ) or from 12.0 to 10.24 per 1000 medication users in January 2009, just after the reimbursement restriction. The trend after policy $(-0.028, \mathrm{p}<0.001)$ was significantly different from the trend before policy change $(-0.011, \mathrm{p}=0.019)$; the monthly trend change after policy was -0.017 (95\% CI -0.031 to 0.003 ) per 1000 medication users. Therefore, the policy change had an initial and long-term effect on the incidence of BZD use.

\section{The effect of the policy on the intensity of BZD use: prevalence} of incidental, regular and chronic use

Figure 2B shows the trend and level effect of the prevalence of incidental $\left(R^{2}=0.97\right)$, regular $\left(R^{2}=0.98\right)$ and chronic $\left(R^{2}=0.98\right)$ use, with a distinction between raw and estimated trends and upper and lower confidence limits. In 2002, the estimated prevalence per 1000 medication users was 78.1 (95\% CI 73.7 to 82.5) for incidental, 59.9 (95\% CI 56.8 to 63.1 ) for regular and 60.2 (95\% CI 57.4 to 63.1) for chronic use. Before policy there was an estimated annual reduction of $-0.700(p=0.018)$ for regular and -1.052 ( $\mathrm{p}=0004)$ for long-term use. The estimated prepolicy trend shows an increase in the prevalence of incidental use from 2002 to $2008(0.888, \mathrm{p}=0.039)$. The absolute-level effects for incidental use are -15.0 (95\% CI -20.2 to 9.9$)$, for regular use -11.1 (95\% CI -14.5 to 7.7$)$ and for chronic use -8.4 (95\% CI -12.1 to 4.7$)$ per 1000 medication users. The relative-level effects are shown in table 3. The postpolicy trend for incidental use $(-2.736$, $\mathrm{p}=0.002$ ) was significantly different from the trend before policy $(0.888, \mathrm{p}=0.039)$; the yearly trend change after policy was -3.624 (95\% CI -4.996 to 2.252$)$ per 1000 medication users. Therefore, the policy had an initial and long-term effect on the prevalence of incidental use. The postpolicy trends for regular $(-1.003, p=0.034)$ and chronic $(-0.915, \mathrm{p}=0.069)$ use were not significantly different from the prepolicy trends; the trend changes after policy were -0.304 (95\% CI -1.204 to 0.596 ) for regular and 0.136 (95\% CI -0.858 to 1.130 ) for chronic use. Therefore, the policy change had only an initial effect on the prevalence of regular and chronic use.

Table 3 summarises the effects of the policy on the volume (dispensing rate and dispensed DDD rate), the incidence and the intensity (prevalence of incidental, regular and chronic use) of BZD use, as previously described.

\section{The effect of the reimbursement restriction on the discontinuation of BZD treatment}

The Kaplan-Meier curves for the 5-year period before and after policy change, illustrating the time to discontinuation after the start date of the first filled BZD prescription, showed no visual difference (see online supplementary figure 1).

Cox proportional hazards analysis was used to compare the risk of discontinuation between patients starting BZDs before (2004-2008) and after (2009-2013) the reimbursement restriction. A small but significant difference 


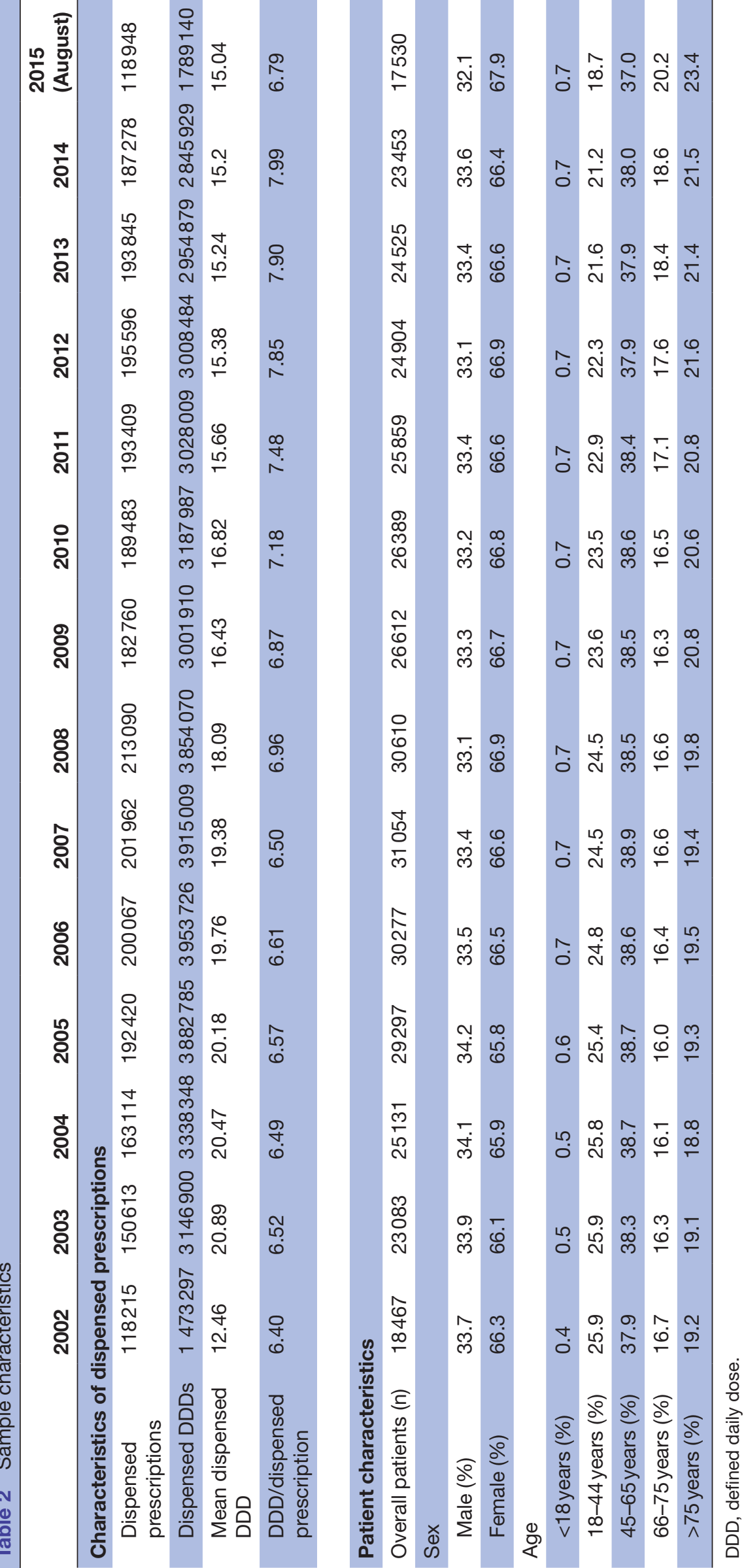



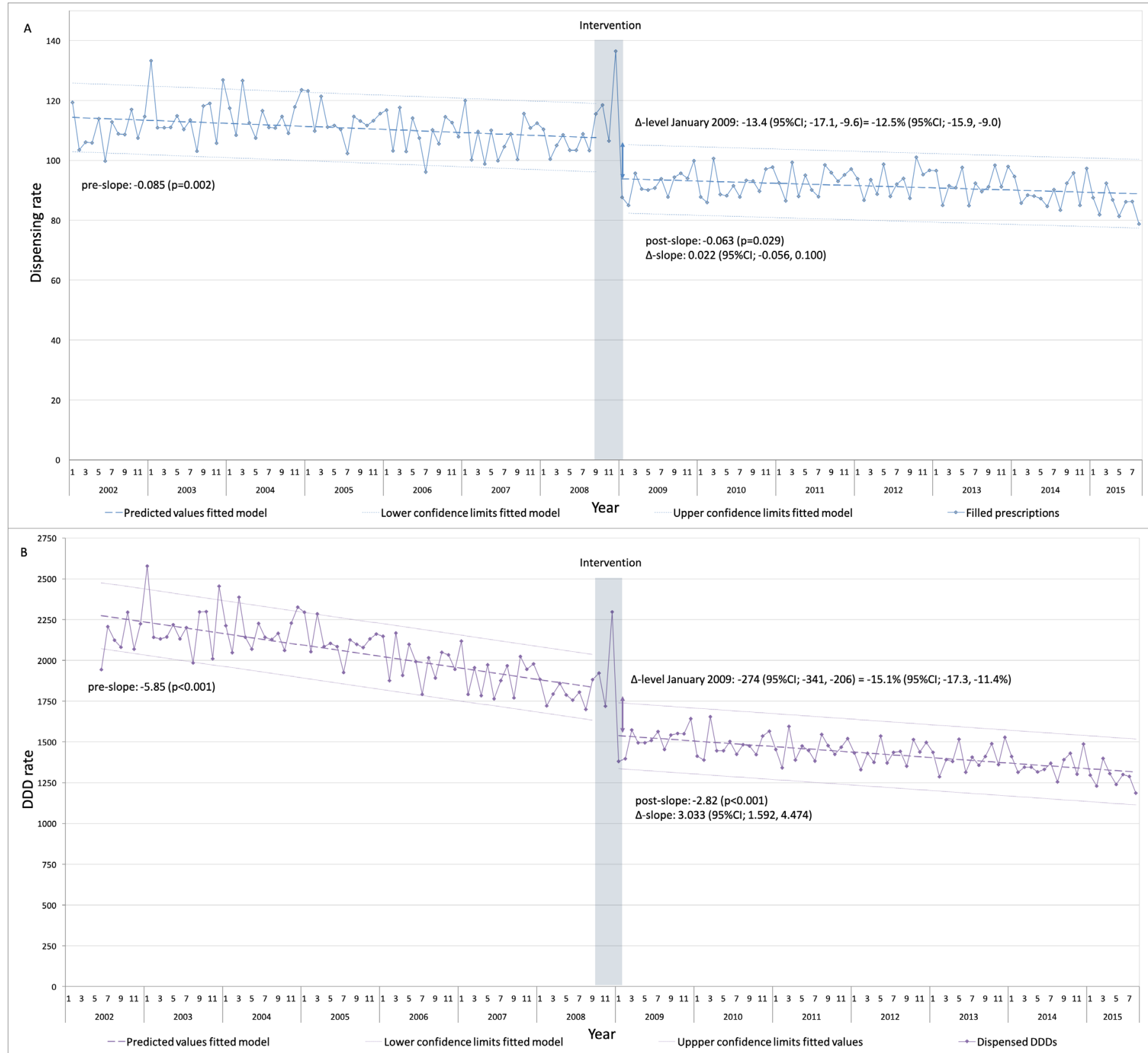

Figure 1 The volume of benzodiazepine (BZD) use over time. (A) The dispensing rate, the total dispensed prescriptions per month per 1000 medication users. (B) The defined daily dose (DDD) rate, the total DDDs dispensed per month per 1000 medication users.

in discontinuation rate was observed $(\mathrm{HR}=1.013 ; 95 \% \mathrm{CI}$ 1.004 to 1.022$)$, indicating that patients who started treatment had a higher chance of discontinuation in the 5-year period after the policy change. Adjusting for age, sex and socioeconomic status as potential confounders did not result in a change of more than $10 \%$ of the HR, so they were not included in the final model.

\section{DISCUSSION}

This study is the first study which evaluates the initial as well as the long-term effects of the reimbursement restriction policy on BZD use in the Netherlands. Just after the policy change the total number of dispensed prescriptions as well as dispensed DDD dropped significantly. This effect persisted in the years after the policy change. On the patient level the reimbursement policy had a significant initial effect on the prevalence of both incidental, regular and chronic use. This effect was most prominent in regular use. Only in case of incidental use, there was a stronger monthly decrease in the number of users after the reimbursement restriction policy, indicating a long-term effect. A long-term effect on chronic use is lacking. The policy change had a significant initial effect on the overall incidence of BZD use. The monthly decrease in incidence is greater after policy, which is a strong indication for a long-term effect. When we compare 


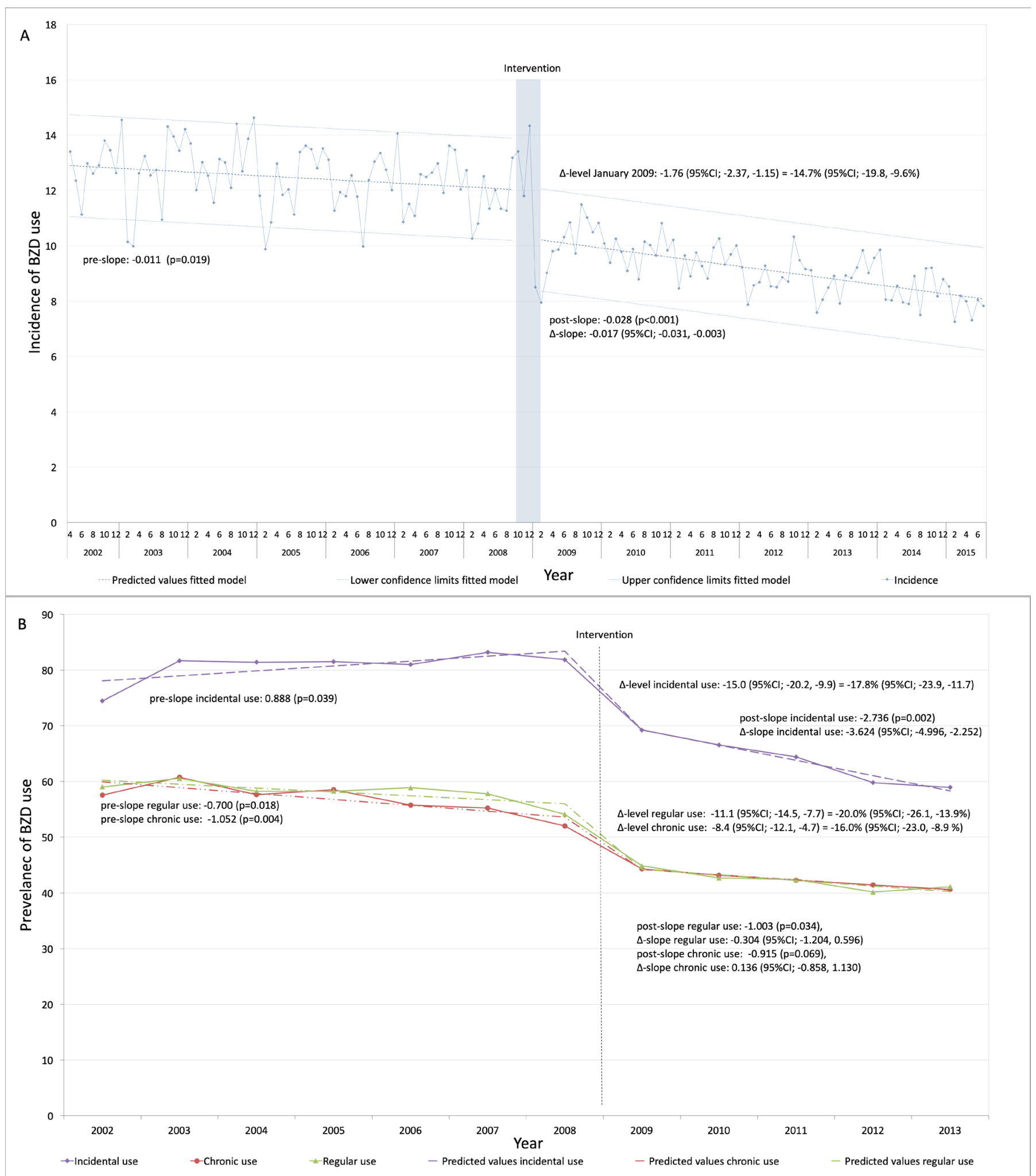

Figure 2 Incidence and intensity of benzodiazepine (BZD) use over time. (A) Incidence per month per 1000 medication users. (B) Prevalence of incidental, regular and chronic use of BZD per calendar year per 1000 medication users.

discontinuation of treatment in the 5-year period before and after the restriction policy the reimbursement had a statistical significant effect (HR 1013). This effect is small and does not appear to be of clinical significance.
Absence of a long-term effect on chronic use could be caused by the proportion of patients with the indication of epilepsy and multiple psychiatric disorders, where reimbursement is maintained. Moreover, BZD dependency 
Table 3 Summary of effects of reimbursement restriction of BZDs on the volume, incidence and prevalence of benzodiazepine use

\begin{tabular}{llll}
\hline & Effects of policy change & $\begin{array}{l}\text { Relative-level effect } \\
\text { (95\% Cl) }\end{array}$ & $\begin{array}{l}\text { Delta slope (trend) } \\
\text { (95\% Cl) }\end{array}$ \\
\hline Dispensing rate & Initial effect only & $-12.5 \%(-15.9 \%$ to 9.0\%) & $0.022(-0.056$ to 0.100$)$ \\
Dispensed DDD rate & $\begin{array}{l}\text { Initial effect and long-term } \\
\text { opposite effect }\end{array}$ & $-15.1 \%(-17.3 \%$ to 11.4\%) & $3.033(1.592$ to 4.474) \\
\hline Incidence & Initial and long-term effects & $-14.7 \%(-19.8 \%$ to 9.6\%) & $-0.017(-0.031$ to 0.003) \\
\hline $\begin{array}{l}\text { Prevalence incidental use } \\
\text { Prevalence regular use }\end{array}$ & Initial and long-term effects & $-17.8 \%(-23.9 \%$ to 11.7\%) & $-3.624(-4.996$ to 2.252) \\
Prevalence chronic use & Initial effect only & $-20.0 \%(-26.1 \%$ to 13.9\%) & $-0.304(-1.204$ to 0.596) \\
\hline
\end{tabular}

BZD, benzodiazepine; DDD, defined daily dose.

plays a bigger role in this subgroup, which might have an impact on discontinuation rates. Unfortunately, we have no data about indications and reimbursement on the individual patient level. Another mechanism we observe in daily practice can also play a part; prescribers can declare that a patient has multiple psychiatric disorders, although it is not true, only to keep the drug reimbursed. This could occur more frequently in chronic use of BZDs.

Another possible explanation for this phenomenon could be the difference in financial threshold in case of incidental use. The price of BZDs is relatively low, about $€ 0.5-€ 2$ for a month, compared with the pharmacist's service fee for dispensing (€6). The pharmacist's fee for dispensing a first prescription $(€ 12)$ is about twice as high as for a subsequent prescription, which means that the financial threshold to start exceeds the threshold to continue BZD use. This could be an explanation for the fact that the long-term impact on the incidence and the prevalence of incidental use is positive and lacking in case of both regular and chronic use. Another argument is that it might be more difficult for physicians to stop treatment of individual patients than to prevent initiation, especially when it comes to addictive medication. Medication prescribing is a complex process where behaviour and dynamics regarding initiation are often less complicated than in case of medication cessation.

In addition to reduce chronic use, another aim of the reimbursement restriction was to reduce drug expenditures. Unfortunately, in the PHARMO Outpatient Pharmacy Database, data on costs and coverage status of the dispensed BZD were missing. In 2009, the year after the policy change, about $32 \%$ of dispensed prescriptions were covered by health insurance and $€ 79$ million was spent on BZDs, of which $€ 56$ million was paid by the users themselves. ${ }^{27}$ While health insurers paid only $32 \%$ of all BZDs in 2009, in 2017 that share grew to almost half. ${ }^{28}$ The absolute number of reimbursed prescriptions increased annually from 3350 million in 2009 to 5033 million in 2017. As a result, the annual net saving of $€ 70$ million for the years 2009-2013, calculated by the Dutch Ministry of Healthcare in 2008, has not been achieved. This is a simple way of estimating the intended financial effects on an annual basis. Only an in-depth (health-economic) analysis of health gain and loss, healthcare utilisation and substitution to other (pharmaco)therapies, like antidepressants or psychotherapy, can reveal the true budget and health impact of the reimbursement restriction policy. The International Task Force on Benzodiazepines suggests that warnings against the negative effects of BZD might be influenced by the pharmaceutical industries in order to promote the use of newer patented alternatives like the serotonin reuptake inhibitors for anxiety. ${ }^{29}$ These approaches are beyond the scope of this article.

The strengths of this study are the large sample size, the long follow-up, the large amount of time frames and the presence of data of all outpatient prescriptions, including those initiated in secondary care. This makes it possible to focus on short-term and long-term effects. Another strength is use of an ITS design to evaluate the effect of this policy change. This analysis is the golden standard for evaluation of the effects of policy change.

This study has several limitations. First, it is difficult to attribute the observed changes in BZD use to a single intervention, the reimbursement restriction policy, because many confounding factors change in time. However, to our knowledge there were no other health system changes that could be a rival explanation for the observed changes. Second, due to PHARMO regulations, only a $10 \%$ random sample of PHARMO database was obtained and analysed. Nevertheless, the statistical significance of our analysis shows that the size of the data set is sufficient. Finally, in this study dispensed prescriptions were used as an approximation of BZD use. This may not always be accurate as in fact not all dispensed prescriptions have led to their consumption.

Not only Dutch policymakers have chosen to apply financial incentives to reduce BZD use. In Italy, exclusion from reimbursement in 1994 was not enough to reduce the use of BZDs. Despite the reimbursement policy the total BZDs sold from 1989 to 1999 showed a $53 \%$ increase in Italy. ${ }^{30}$ Although a French pay-for-performance strategy had a modest effect on the achievement of GPs regarding BZD indicators, ${ }^{16}$ it did not lead to the intended decrease of the use of BZDs in 2012. ${ }^{31}$ In a US policy, exclusion 
from the Medicare Part D formulary in 2006 led to an immediate and sustained drop of $5 \%$ in number of BZD prescriptions filled by seniors. ${ }^{32}$

Compared with these policies the effect of the Dutch reimbursement restriction policy is high. In contrast, compared with the effect of the New York State Regulatory action in 1989 that required triplicate forms for BZD prescribing which created a higher bureaucratic threshold for BZD prescribing which resulted in a $60 \%$ reduction in $\mathrm{BZD}$ use, ${ }^{33}$ the effect of the reimbursement restriction in the Netherlands is modest.

A decrease in the use of BZDs does not automatically lead to a reduction of the negative events with which they are associated in the literature. For example, Wagner et al showed that this policy, despite this substantial reduction in the use of BZDs, did not lead to a decrease in hip fractures. ${ }^{15}$ So, substantial reductions in the use of BZD do not necessary lead to expected clinical benefits.

Not only in case of BZDs are introducing financial incentives used to influence the use of prescription drugs. Green et al reviewed the effects of reimbursement restrictions on the use of several drug classes. ${ }^{34}$ Due to substantial differences in objectives, context and the presence of alternatives, it is difficult to generalise the results and to compare with the outcomes of this study. Green et al stated that policy design needs to be based on research quantifying the harm and benefit profiles of target and alternative drugs to avoid unwanted health system and health effects.

When policy changes are so profound and affect so many people, it is the responsibility of the authorities to make a sound assessment and share it with society. This information provides essential insights into 'what to do' and 'what not to do' in drug reimbursement policy. This allows policymakers to learn from previous initiatives and from initiatives abroad, and enables them to deploy reimbursement policy in an evidence-based manner. However, success of reimbursement policy is difficult to predict and highly dependent on purpose and context and a result of the complex interaction between social, cultural, economic and systemic factors. Neglecting this complex dynamic can cause failure of copied successful policies.

Despite these limitations, this study provides us important insights into the effects of the policy on the use of BZDs in the Netherlands and gives direction for follow-up research. Does this policy lead to intended or unintended substitution; the shift to other medicines or therapies or substance abuse? And, are there differences between prescribers, different BZDs, age groups and socioeconomic status? It is also important to investigate whether the decrease in the use of BZDs actually leads to a reduction of the associated adverse events like addiction, fall incidents, hip fractures and the impact on sickness absence and social costs in the Netherlands.

This is the first study with an ITS design on the initial and long-term effects of the 2009 reimbursement restriction policy on BZD use in the Netherlands. The policy change has a significant initial effect on the volume and incidence of BZD use. In addition to an initial effect, there is a long-term effect in case of incidental use and overall incidence. Although there is a significant initial effect, the long-term effect on the chronic use of BZD, the main purpose of the reimbursement restriction, is lacking.

\section{Author affiliations}

${ }^{1}$ Division of Pharmacoepidemiology and Clinical Pharmacology, Faculty of Science, Utrecht Institute for Pharmaceutical Sciences, Utrecht University, Utrecht, The Netherlands

${ }^{2}$ Clinical Pharmacy, Medisch Centrum Haaglanden, Den Haag, Zuid-Holland, The Netherlands

${ }^{3}$ Research Group Innovations of Pharmaceutical Care, University of Applied Sciences Utrecht, Utrecht, The Netherlands

${ }^{4}$ Erasmus School of Health Policy and Management/Health Care Governance, Erasmus Universiteit Rotterdam, Rotterdam, Zuid-Holland, The Netherlands

${ }^{5}$ TRANZO, Tilburg School of Social and Behavioral Sciences, Tilburg University, Tilburg, Brabant, The Netherlands

${ }^{6}$ Division of Pharmacoepidemiology and Clinical Pharmacology, Faculty of Science, Utrecht Institute for Pharmaceutical Sciences, Utrecht, The Netherlands

Acknowledgements The authors acknowledge Patrick Souverein, assistant professor, for his kind help with the data analysis.

Contributors LJS conceived the presented idea. LJS, ERH, RJ and TCGE developed the theory and design. LJS and ERH performed the analysis and interpretation of data. RJ and TCGE verified the analytical methods. All authors discussed the results and contributed to the final manuscript.

Funding The entire study was conducted without external funding.

Competing interests None declared.

Patient consent for publication Not required.

Ethics approval No research ethics approval was necessary for this study, because it was based on non-personalised retrospective health utilisation data, used in accordance with Dutch and EU privacy legislation. The use of the PHARMO data is controlled by the independent Compliance Committee STIZON/PHARMO Institute. Each study requires permission from this Committee. Prior permission is required depending on the detail of use of data. For each study, the research question, the data used for the study, the methods used to analyse the data and the people/organisations who commissioned the study have to be described. All decisions of the Compliance Committee STIZON/PHARMO Institute are based on the applicable legislation in the Netherlands, for example, the Personal Data Protection Act and the Medical Treatment Contract Act. Within this legal framework, the Code of Conduct 'Use of Data in Health Research' is an important document for the interpretation of the use of this kind of data for scientific research in the Netherlands, and is approved by the Dutch Data Protection Authority.

Provenance and peer review Not commissioned; externally peer reviewed.

Data availability statement Data are available upon reasonable request.

Open access This is an open access article distributed in accordance with the Creative Commons Attribution Non Commercial (CC BY-NC 4.0) license, which permits others to distribute, remix, adapt, build upon this work non-commercially, and license their derivative works on different terms, provided the original work is properly cited, appropriate credit is given, any changes made indicated, and the use is non-commercial. See: http://creativecommons.org/licenses/by-nc/4.0/.

\section{REFERENCES}

1. Billioti de Gage S, Bégaud B, Bazin F, et al. Benzodiazepine use and risk of dementia: prospective population based study. BMJ 2012;345:e6231.

2. Billioti de Gage S, Moride Y, Ducruet T, et al. Benzodiazepine use and risk of Alzheimer's disease: case-control study. BMJ 2014;349:g5205.

3. Pariente A, Dartigues J-F, Benichou J, et al. Benzodiazepines and injurious falls in community dwelling elders. Drugs Aging 2008;25:61-70. 
4. Xing D, Ma XL, Ma JX, et al. Association between use of benzodiazepines and risk of fractures: a meta-analysis. Osteoporos Int 2014;25:105-20.

5. Cumming RG, Le Couteur DG. Benzodiazepines and risk of hip fractures in older people: a review of the evidence. CNS Drugs 2003;17:825-37.

6. Smink BE, Egberts ACG, Lusthof $\mathrm{KJ}$, et al. The relationship between benzodiazepine use and traffic accidents: a systematic literature review. CNS Drugs 2010;24:639-53.

7. Parsaik AK, Mascarenhas SS, Khosh-Chashm D, et al. Mortality associated with anxiolytic and hypnotic drugs-A systematic review and meta-analysis. Aust N Z J Psychiatry 2016;50:520-33.

8. Bachhuber MA, Hennessy S, Cunningham CO, et al. Increasing benzodiazepine prescriptions and overdose mortality in the United States, 1996-2013. A m J Public Health 2016.

9. Soyka M. Treatment of benzodiazepine dependence. N Engl J Med 2017;376:1147-57.

10. López-Muñoz F, Álamo C, García-García P. The discovery of chlordiazepoxide and the clinical introduction of benzodiazepines: half a century of anxiolytic drugs. J Anxiety Disord 2011;25:554-62.

11. Het aantal gebruikers van slaap- en kalmeringsmiddelen, 2002 - 2016. Zorginstituut Nederland, 2018. Available: https://www.gipdatabank.nl/ databank\#/g//85 ben/gebr/bijlage [Accessed 11 Jun 2018].

12. Kurkoa TAT, Saastamoinen LK, Tahkapaa S, et al. Long-term use of benzodiazepines : Definitions. prevalence and usage patterns - a systematic review of register-based studies 2015;30:1037-47.

13. Clay E, Falissard B, Moore N, et al. Contribution of prolonged-release melatonin and anti-benzodiazepine campaigns to the reduction of benzodiazepine and Z-drugs consumption in nine European countries. Eur J Clin Pharmacol 2013;69:1-10.

14. Cunningham CM, Hanley GE, Morgan S. Patterns in the use of benzodiazepines in British Columbia: examining the impact of increasing research and guideline cautions against long-term use. Health Policy (New York) 2010.

15. Wagner AK, Ross-Degnan D, Gurwitz JH, et al. Effect of new York state regulatory action on benzodiazepine prescribing and hip fracture rates. Ann Intern Med 2007;146:96-103.

16. Michel-Lepage A, Ventelou B. The true impact of the French pay-forperformance program on physicians' benzodiazepines prescription behavior. Eur J Health Econ 2016;17:723-32.

17. Pollmann AS, Murphy AL, Bergman JC, et al. And Z-drugs in community-dwelling adults: a scoping review. BMC Pharmacol Toxicol 2015;16.

18. Godman B, Shrank W, Andersen M, et al. Policies to enhance prescribing efficiency in Europe: findings and future implications. Front Pharmacol 2011:1-16.
19. Ministerie van Volksgezondheid Welzijn en sport. Rijksbegroting 2009. Vaststelling van de begrotingsstaat van het Ministerie van Volksgezondheid, Welzijn en Sport (XVI) voor het jaar 2008;2009.

20. Hoebert JM, Souverein PC, Mantel-Teeuwisse AK, et al. Reimbursement restriction and moderate decrease in benzodiazepine use in general practice. Ann Fam Med 2012;10:42-9

21. Kollen BJ, van der Veen WJ, Groenhof F, et al. Discontinuation of reimbursement of benzodiazepines in the Netherlands: does it make a difference? BMC Fam Pract 2012;13:111.

22. Enthoven AC, van de Ven WPMM. Going Dutch--managedcompetition health insurance in the Netherlands. $N$ Engl J Med 2007;357:2421-3.

23. Wagner AK, Soumerai SB, Zhang F, et al. Segmented regression analysis of interrupted time series studies in medication use research. J Clin Pharm Ther 2002;27:299-309.

24. Bernal JL, Cummins S, Gasparrini A. Interrupted time series regression for the evaluation of public health interventions: a tutorial. Int J Epidemiol 2017;46:348-55.

25. Lagarde $\mathrm{M}$, do Hto. How to do (or not to do)... Assessing the impact of a policy change with routine longitudinal data. Health Policy Plan 2012;27:76-83.

26. Cochrane effective practice and organisation of care (EPOC). interrupted time series (its) analyses. EPOC Resources for review authors 2017

27. Kengetallen SF. Benzodiazepinegebruik vooral uit eigen ZAK. Pharm Weekbl 2010;145.

28. Anonimous. Gebruik benzodiazepines vorig jaar verder afgenomen Hoeveelheid voor rekening van zorgverzekeraar blijft toenemen. Pharm Weekbl 2018;3:13-14.

29. Balon R, Chouinard G, Cosci F, et al. International Task force on benzodiazepines. Psychother Psychosom 2018;87:193-4.

30. Barbui C, Campomori A, Mezzalira L, et al. Psychotropic drug use in Italy, 1984-99: the impact of a change in reimbursement status. Int Clin Psychopharmacol 2001:16:227-33.

31. Rat C, Penhouet G, Gaultier A, et al. Did the new French pay-forperformance system modify benzodiazepine prescribing practices? BMC Health Serv Res 2014;14:301.

32. Chen H, Nwangwu A, Aparasu R, et al. The impact of Medicare Part $D$ on psychotropic utilization and financial burden for communitybased seniors. PS 2008;59:1191-7.

33. Weintraub M, Singh S, Byrne L, et al. Consequences of the 1989 New York state triplicate benzodiazepine prescription regulations. JAMA 1991;266:2392-7.

34. Green CJ, Maclure M, Fortin PM, et al. Pharmaceutical policies: effects of restrictions on reimbursement. Cochrane Database Syst Rev 2010;19. 